\title{
Studying Structural, Morphological And Optical Properties of Cadmium Oxide
}

\author{
1Nadia J.Ghdeeb, 2Eman K. jabur, 2Noha H. Harb, 1Nisreen.Kh.abdalameer
}

${ }_{1}$ Department of Physics, College of science, University of Mustansiriya, Baghdad, Iraq.

2,2,1Department of Physics, collage of Science for Women University of Baghdad, Baghdad, Iraq.

Correspondence Author: Nadia J.Ghdeeb, Department of Physics, College of science, University of Mustansiriya, Baghdad, Iraq.

Received date: 10 January 2018, Accepted date: 28 February 2018, Online date: 10 March 2018

Copyright: (C) 2018 Nadia J.Ghdeebet al.This is an open-access article distributed under the terms of the Creative Commons Attribution License, whichpermits unrestricted use, distribution, and reproduction in any medium, provided the original author and source are credited.

\begin{abstract}
$\mathrm{CdO}$ is an n-type semiconductor with a rock-salt crystal structure (fcc) and possesses a direct band gap of $2.2 \mathrm{eV}$. Its high electrical conductivity and high optical transmittance in the visible region of solar spectrum along with a moderate reflective index make it useful for various applications, photodiodes, gas sensors, etc. $\mathrm{CdO}$ and CdO:Cuthin films have been prepared on glass substrates at $380 \mathrm{C}^{\circ}$ substrate temperature by the chemical spray pyrolysis(CSP) method using an aqueous solution with varying copper concentrations. The thickness of the films have been measured to be $(200 \pm 5) \mathrm{nm}$. The films have been characterized to evaluate the structure ,morphology, transmittance and optical energy band gab. X-ray diffraction(XRD) studies show that the films are polycrystalline with cubic structures. The optical band gab energies and types of optical transition and absorption of the films have been determined from the optical transmittance spectra. The optical absorption

studies in the wavelength range 300-900 nm show that band gap energy values of the films increase from (2 to 3 )eV as the $\mathrm{Cu}$ concentration increases.
\end{abstract}

Key words: CdO films, structure, morphological, optical properties

\section{INTRODUCTION}

Cadmium Oxide is a chemical compound of cadmium, as it does not dissolve in water or in the bases, but dissolves in acids and ammonia salts [1,2], and disintegrates at high temperatures.[3] we get cadmium oxide from the extreme heating of cadmium element [2]. Semi-conductor cadmium belongs to the group (II-VI) (I, VI) of the periodic table, with cubic crystalline structure and a fcc unit. This is similar to the synthesis of sodium chloride (NaCl) [4, 3].

Cadmium oxide is a semi-conductive material from the transparent conductivity oxides group (TCO) which has distinct properties such as a large energy gap, high permeability in the spectrum visible area, high mobility of conductors, electrical conductivity approach to the conductivity of n-type metals, Are required, with wide applications in optoelectronic devices, photovoltaic devices and projectors. [5-6] Cadmium oxide has a high conductivity resulting from the presence of cadmium atoms in interstitial sites or due to oxygen vacuums [3]. Cadmium oxide has a high absorption factor that can be used in solar systems to increase its efficiency in photovoltaic cells and is used as window layers in Hetrojunction Solar Cells and transparent electrodes in solar cell technology. Cell (CdO / CdTe) with a efficiency of $7 \%$ and a successful alternative to the material (CdS) in the system (SnO2 / CdS / CdTe) [7-8]. It is the physical and chemical properties of

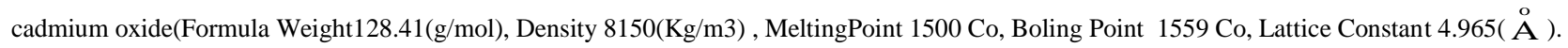

In this study, undoped and $(\mathrm{Cu})$ dual doped $\mathrm{CdO}$ thin films have been deposited by spray pyrolysis method using cadmium chloride and copper chloride $\mathrm{CuCl} 2$ in different concentrations as the solvent and the structural, morphological and optical properties of the films has been studied. We have chosen the spray pyrolysis method because of low cost, easy to control growth parameters, large area of fabrication.

\section{2-Experimental:}

The chloride solution of cadmium chloride is 0.1 molar, which is a source of cadmium ions has been present after it is dissolved in water and copper chloride $\mathrm{CuCl} 2$ in different concentrations. This material is a source of copper, which is the fading element of CdO: cu and for the desired membrane, (25 ml of distilled water), either the required weights were calculated using a sensitive electronic balance of sensitive type (Mettler AE-160) $10^{-4} \mathrm{~g}$.

The following relationship was used to obtain the weight to be melted within the standard above[9].

$\mathrm{M}=(\mathrm{Wt} / \mathrm{Mwt}) .(1000 / \mathrm{V})$

M: Molaric concentration.

Wt: The weight required to melt.

V: Volume of distilled water. Mut:

Molecular weight of matter.

After completing the process of dissolving and obtaining the appropriate solution, leave the solution for a period of time and then filter well by the filter paper until we obtain a clear solution homogenous free of plankton and ready to spray.

Advances in Natural and Applied Sciences 
Leave the films after completing the spraying process for at least one hour after heating the heater until the temperature reaches the room temperature, to avoid cracking when lifted directly, and allow the films to complete the oxidation process.

\section{RESULT AND DISCUSSION}

3.1X-ray Characterization:

The results of the diagnosis showed that X-ray diffraction showed that all films were polycystalline and cubic-type (Figure 1). This was consistent with some published research $[10,11,12,13]$.

The diagnosis also shows the obvious effect of impurities on the crystalline structure of copper-cadmium oxide membranes by $3 \%$ and $5 \%$, Fig.(1b,1c), There were peaks confirming the presence of copper as a defect within the crystal structure, and The results shown in Table (1) were computed according to the Brak Law Eq.(2) and the following relations.[14].

$\mathrm{n} \lambda=2 \mathrm{~d} \sin \theta$

$\mathrm{D}=\frac{0.9 \lambda}{\mathrm{B} \cos \theta}$

Relationship (3) is called Sharer's Law, which represents:

D: Particle size, B: Half width of midpoint.

The following relationship has been calculated by calculating the constant number [15]:

$d=\frac{a}{\sqrt{h^{2}+k^{2}+{ }^{2}}}$

They represent: (a) constant lattac. (hkl)

The results are similar to those found in the American Standard for Testing Materials (ASTM) card for non-porous membranes . As for the deformed membranes, the results showed a change in the values of the d-distance and the values of the lattac constant.

Figure (2) the AFM images for CdO thin films deposited on glass substrate at RT and different concentration. Root mean square values and grain size were listed in Table (2). From the topographic images, The RMS roughness increase of concentration. Also, The grain size decreases with the increasing concentration.
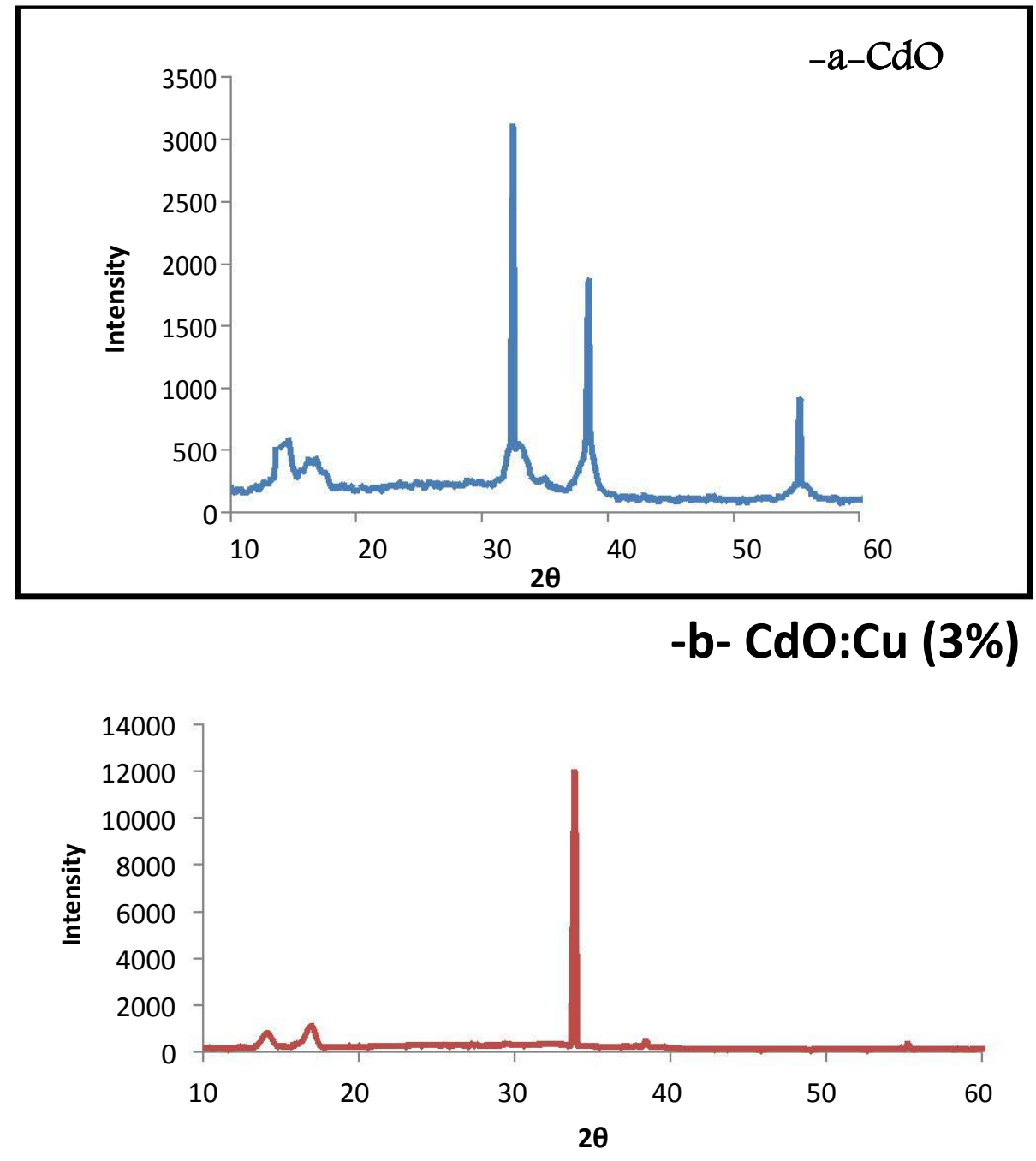


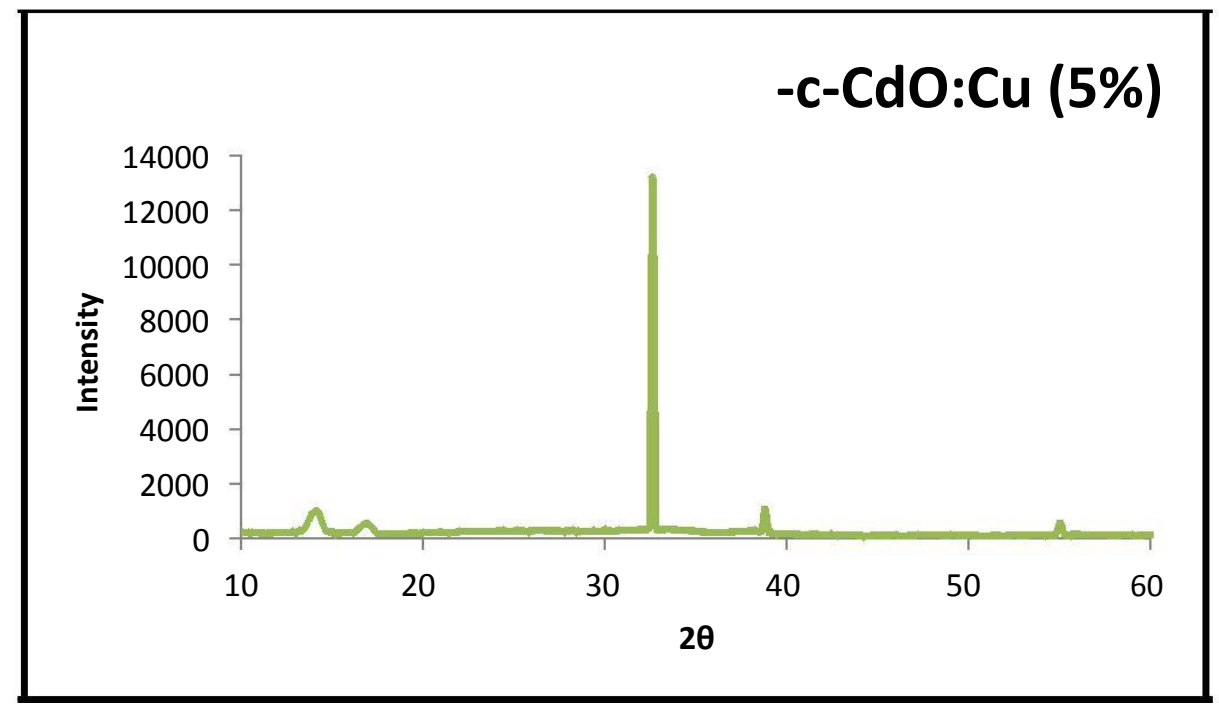

Fig. 1: x-ray diffraction patterns of $\mathrm{CdO}$ and $\mathrm{CdO}: \mathrm{Cu}$ thin film

Table 1: The obtained result of the XRD for $\mathrm{CdO}$ and $\mathrm{CdO}: \mathrm{Cu}$ films

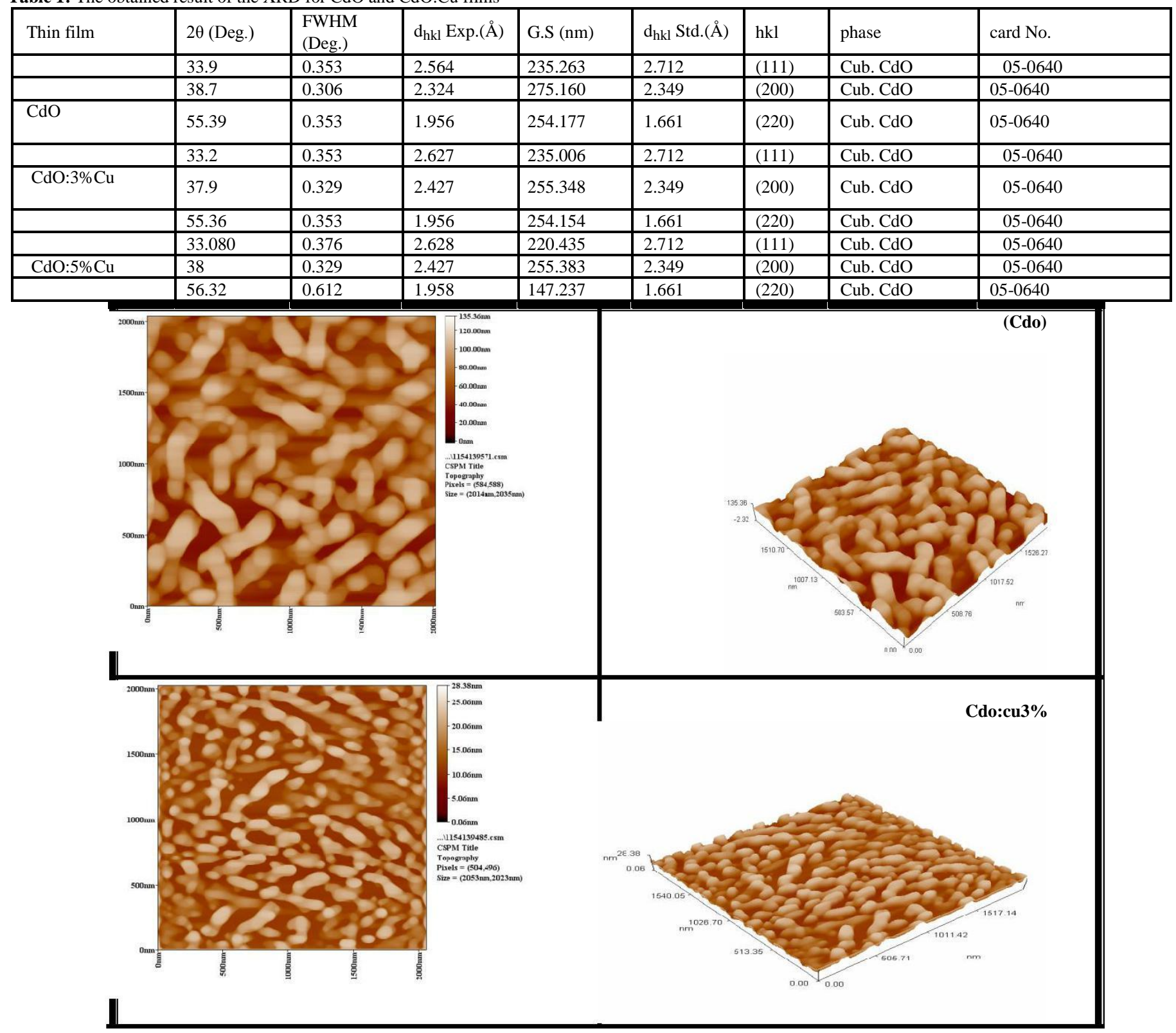




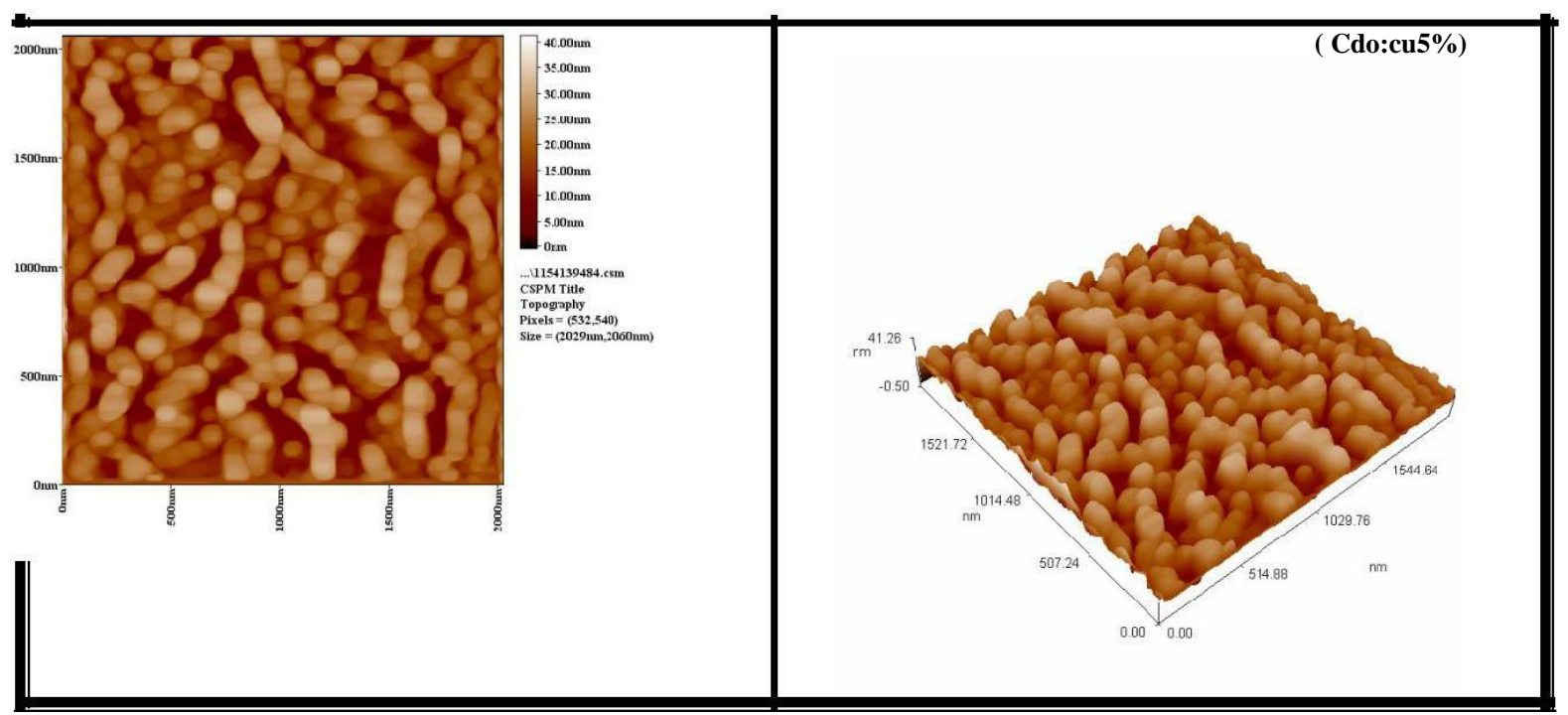

Fig. 2: AFM micrographs of (a)CdO, (b)CdO:Cu(3\%) (c) $\mathrm{CdO}: \mathrm{Cu}(5 \%)$

Table 2: AFM parameters of CdOand CdO:Cu films

\begin{tabular}{|l|l|l|}
\hline RMS [nm] & grain size $(\mathrm{nm})$ & Film \\
\hline 5.35 & 186.1 & $\mathrm{CdO}$ \\
\hline 6.16 & 100.31 & $\mathrm{CdO}: 3 \% \mathrm{Cu}$ \\
\hline 13.9 & 95.17 & $\mathrm{CdO}: 5 \% \mathrm{Cu}$ \\
\hline
\end{tabular}

\subsection{Optical properties:}

Absorption measurements were carried out within the wavelength range (300-900nm) of all membranes prepared at room temperature. From the figure(3) we note that in the case of the uncut $\mathrm{CdO}$ membrane, the absorbance reaches its highest value at wavelength $(300 \mathrm{~nm})$ and then gradually decreases with increasing wavelength to reach the lowest value at wavelength $(900 \mathrm{~nm})$. As for the addition of $\mathrm{Cu}$ and for different percentages $(3,5) \%$ to cadmium oxide, the absorption curves of the affected membranes behave the same as the absorbent nature of the unmixed cadmium oxide, while the absorption values were increased for all wavelength ratios within the wavelength range (300-900) $\mathrm{nm}$.

From the figure(4)we observe that the transmittance spectrum of the uncut $\mathrm{CdO}$ membrane starts at its lowest value at $300 \mathrm{~nm}$ and then appears almost constant within the wavelength range $(300-500 \mathrm{~nm})$ to rapidly rise to wavelength range $(500-900 \mathrm{~nm})$.

As can be seen from the same figure that the deflection leads to a decrease in the values of permeability of all the different deflection rates within the wavelength range.

The coefficient of absorption of the CdO membrane is high $\left(\alpha>10^{4} \mathrm{~cm}^{-1}\right)$ within the same range of energies. This helps to predict direct transitions of this range of energies.

The nature of electronic transitions can be deduced by studying the values of the absorption coefficient and the extent to which these values change with the photon's falling energy. The high values of the absorption coefficient suggest that the probability of electronic transmission is significant and direct transitions occur and that the energies in which these values are calculated are the energy of a direct gap. In the case of corrosive membranes, the nature of the coefficient of absorption coefficient did not change with the addition of impurities. However, the distortion process increased the absorption coefficient values of the corrosive membranes. This increase in the value of the absorption coefficient indicates that the defect led to the generation of donor levels within the restricted energy gap, This is why the photons with low energies are more likely to be absorbed.

The optical energy gap values (Eg) for CdOfilms have been determined using Tauc equation.

$\alpha(h v)=B \llbracket\left(h v-E \_g\right) \rrbracket \wedge r$

Where (B) is constant involving the properties of the bands,(v) frequency of incident photon, $(\mathrm{r})$ is a constant depending on the nature of transition. From figure (7) It can be observed that the energy gap increased with increasing of Cu constrationfrom(2-3)eV.

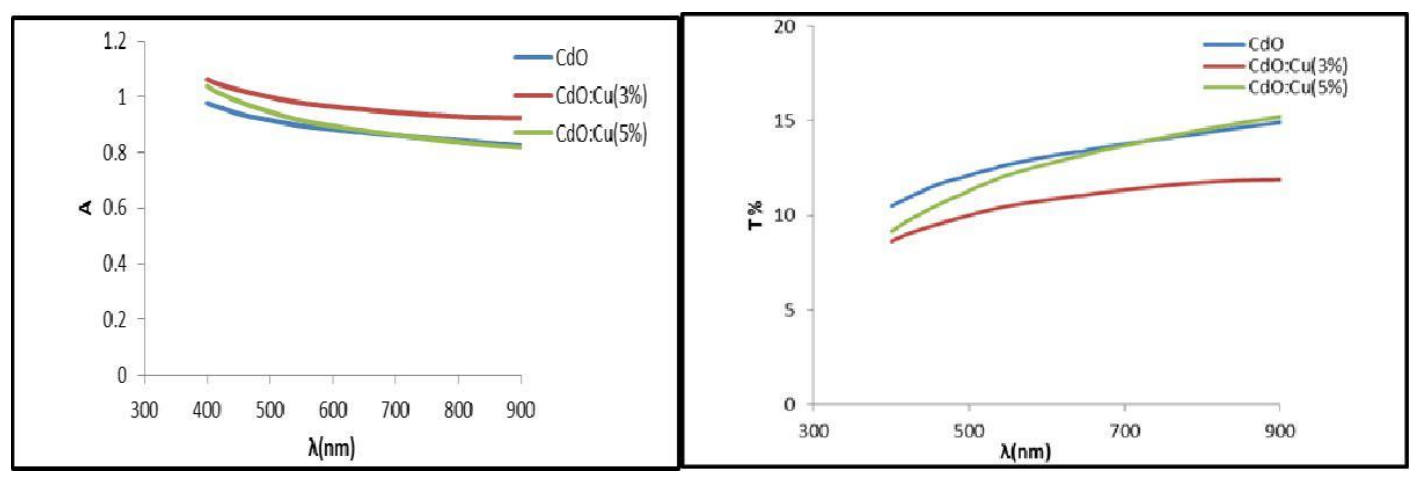

Fig. 3: optical absorption spectra of the CdO thin Fig .4. optical transmittance spectra of the CdO thin film film 

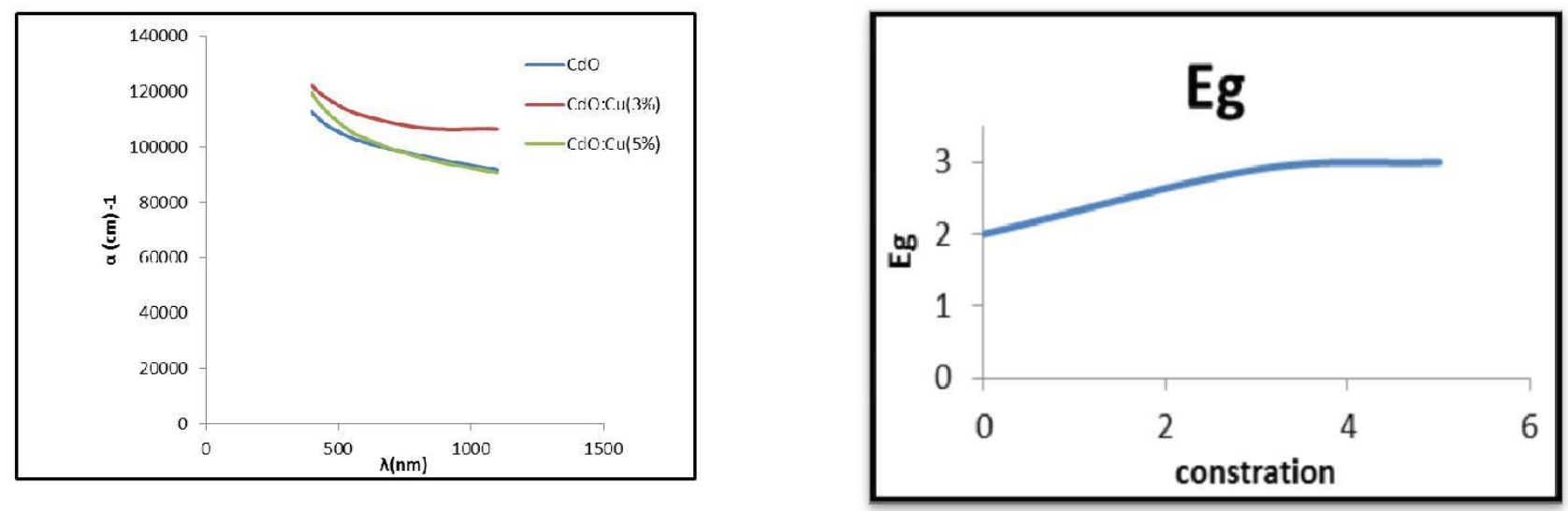

Fig. 5: absorption coefficient of $\mathrm{CdO}$ and $\mathrm{CdO}: \mathrm{Cu}$ thin filmFig.(7):The relationship between the Egand concentration

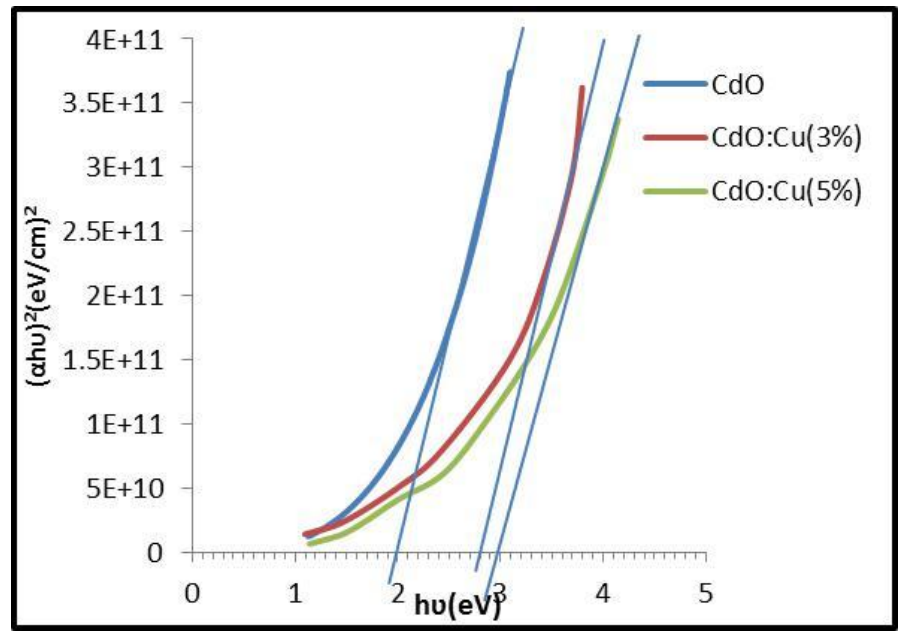

Fig. 6: $(\alpha h v)^{2}$ as a function of hv forCdO and $\mathrm{CdO}: \mathrm{Cu}$ thin film

\section{Conclusion:}

Cadmium sulfide $(\mathrm{CdO})$ were grown by Chemical Spray Pyrolysis at (rt, 380) C . XRD films are polycrystalline of cubic structure for all thin films. From UV-Visible transmittance, absorbance spectra, it was observed that the absorbance spectrum increases with increasing of concentration and the CdO thin films have allowed direct transition.Future Work Preparation of cadmium oxide, which is impregnated with copper, in vacuum vaporization method and compare itsresults with the results of the current study, Study of changing base-base temperature on the optical and electrical properties of copper-cadmium oxide membranes, Study of the effect of fish changes on the visual and structural properties of membranes prepared using image processing techniques.

\section{REFERENCES}

[1] Weast, R.C. and M.J. Astle.,1979. Hand Book of Chemistry and Physics.

[2] S., 1980. Modern Inorganic Chemistry., Dr. Idris Abdelkader, University of Mosul Press.

[3] Jarzberzki, Z.M., 1973. Oxide Semiconductors, pergamon press.

[4] Babcock, J.R., A. Wang, A.W. Metz, N.L. Edleman, M.V. Metz, M.A. Lane, C.R. Kannewurf and T.J. Marks, 2001. "Transparent conducting CdO thin film growth using ahighly volatile, thermally- and air-stable cadmium precursor," Adv. Matls. CVD, 7: 239-242.

[5] Yu Yang., Shujin., Julia E. Medvedeva., John R. Ireland., Andrew W. Metz., Jun Ni., Mark C. Hersan., Arthur J. Freeman., and Tobin J. Marks., J. Am., 2005. Chem. Soc., 127 (8796)

[6] Subramanyam, T.K., B. Srinivasulu Naidu and S. Uthanna, 2000. Physical properties of zinc oxide films prepared by dc reactive magnetron sputtering at different sputtering pressures. Crystal Research and Technology: Journal of Experimental and Industrial Crystallography, 35(10): 1193-1202.

[7] Ferroa, R. and J.A. Rodriguez., 2000. Phys. State. Sol., (B) 220-299.

[8] Og. Daza., AacReadigos., J. Campos., Mis. Nair and Pk Nair, 2001. Modern Phys. Letters, B15 (609).

[9] Abdullah Mohamed MohamedFaree., 2002. Synthesis and Synthesis of Oxidation Zinc with a halogen group prepared by chemical deposition method. Faculty of Education, University of Mustansiriya.

[10] Faizullah., A.F.M., M.K.R. Khan, M. Mozibur Rahman, 2013. Pyrolized growth of (Al, N) dual doped CdO thin films andstudy of structural, surface morphology and opto-electrical properties,International. Journal of Materials Science and Applications, 2(4): 124-127.

[11] Z.Serbetcia., B., A.A. Gunduzb, F. Al-Ghamdic, K. Al-Hazmic, F. Ar_ka., El-Tantawyd, F. Yakuphanogluc and W.A. Farooqf, 2014. Determination of Optical Constants of Nanocluster CdO Thin Films Deposited by Sol_Gel Technique. ACTA PHYSICA POLONICA A, 126: 3.

[12] Abdul-Hussein, K. Elttayef, Hayder M. Ajeel, Ausama, I. Khudia, 2013. Effect of annealing temperature and doping with Cu onphysical properties of cadmium oxide thin films. $\mathrm{j}$ mater res technol, 2(2): 182-187.

[13] Ghaida Salman1., Eman Kareem, Asama N. Naje, 2014. Optical and electrical properties of CU doped CdO thin films for detector applications. IJISET International Journal of Innovative Science Engineering\& Technology, 1: 6.

[14] Zhang., J.P., G. He, L.Q. Zhu, M. Liu, S.S. Pan, L.D. Zhang, 2007. Applied Surface Science., 253: 9414.

[15] Dhanam, M., R. Rajeev, P.K. Parbhu., Manoj, 2008. Materials Chemistry and Physics, 107: 289. 